\title{
Discrete and continuous model of three-phase linear induction motors considering attraction force and end-effects
}

\author{
Nicolás Toro-García ${ }^{1}$, Yeison Alberto Garcés-Gómez ${ }^{2}$, Fredy E. Hoyos ${ }^{3}$ \\ ${ }^{1}$ Department of Electrical and Electronics Engineering and Computer Sciences, Universidad Nacional de Colombia - Sede \\ Manizales, Colombia \\ ${ }^{2}$ Unidad Académica de Formación en Ciencias Naturales y Matemáticas, Universidad Católica de Manizales, Colombia \\ ${ }^{3}$ Facultad de Ciencias, Escuela de Física, Universidad Nacional de Colombia - Sede Medellín, Colombia
}

\begin{tabular}{l}
\hline Article Info \\
\hline Article history: \\
Received Mar 12, 2020 \\
Revised Jun 10, 2020 \\
Accepted Jun 26, 2020 \\
\hline Keywords: \\
Continuous time model \\
Discrete control systems \\
Discrete time model \\
Linear induction motors \\
Non-linear behaviors
\end{tabular}

Non-linear behaviors

\begin{abstract}
The continuous model of the linear induction motor (LIM) has been made considering the edge effects and the attraction force. Taking the attraction force into account is important when considering dynamic analysis when the motor operates under mechanical load. A laboratory prototype has been implemented from which the parameters of the equivalent LIM circuit have been obtained. The discrete model has been developed to quickly obtain computational solutions and to analyze non-linear behaviors through the application of discrete control systems. In order to obtain the discrete model of the LIM we have started from the solution of the continuous model. To develop the model, the magnetizing inductance has been considered, which reflects the edge effects. In the results, the model is compared without considering the edge effects or the attraction force with the proposed model.
\end{abstract}

This is an open access article under the CC BY-SA license.

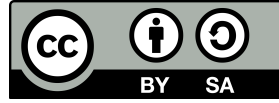

\section{Corresponding Author:}

Y. A. Garcés-Gómez,

Unidad Académica de Formación en Ciencias Naturales y Matemáticas,

Universidad Católica de Manizales,

Cra 23 No 60-63, Manizales, Colombia.

Email: ygarces@ucm.edu.co

\section{INTRODUCTION}

The linear induction motor (LIM) was invented and patented more than a hundred years ago being impractical due to the difficulties in its construction by not being able to have small air space without roughness in addition to not being able to achieve good efficiency factors. Nowadays, technological advances have allowed the LIM to have greater importance, extending its use to important industrial and research applications [1-7]. Linear induction motors are three-phase AC devices that work by the general principles of electromechanical energy transformation like other induction motors and are constructed for to produce movement on a straight line. Although are named "Linear" the mathematical models are nonlinear and due to symmetrical missing in their construction is necessary to consider effects that not are present in the rotary electric machines.

When the topology of a machine is modified, which is the case of the LIM with the RIM (rotary induction machine), the design and operating conditions are also modified. Specifically, different phenomena appear in the magnetic circuit that must be re-modelled. This leads to the development of new theories $[1,2,4]$. 
When it is required to generate a linear movement from RIM, the use of mechanical elements is necessary, this can be avoided with the use of LIM. In addition to eliminating the use of mechanical elements, the latter have the advantages of high acceleration and deceleration capacity, use in levitation systems by normal magnetic forces, lower maintenance costs, low noise, possibility of use in systems with curves and slopes, braking that does not depend on the system conditions, among others [8-12].

There is little work on sampling LIM dynamics; therefore, it is of great importance to investigate an accurate representation of the sampled data of the complete dynamics of linear induction motors, and to design slide controllers at discrete time [7, 13]. With respect to the non-linear models of control strategies applied to LIMs, an in-depth review is made of in $[7,14,15]$, also in the terms of the mathematical model. The physical model of the LIM has been developed to model the figure system as shown in Figure 1. The construction aspects of the LIM have been fully developed in [7, 16]. The organization of the document is as follows. Section 2 develops the modelling of the linear induction motor taking into account the effects of edges and forces in the equivalent circuit which is then discretized for comparison with the continuous model. Section three implements the whole system and compares the results to conclude with the conclusions of the work.

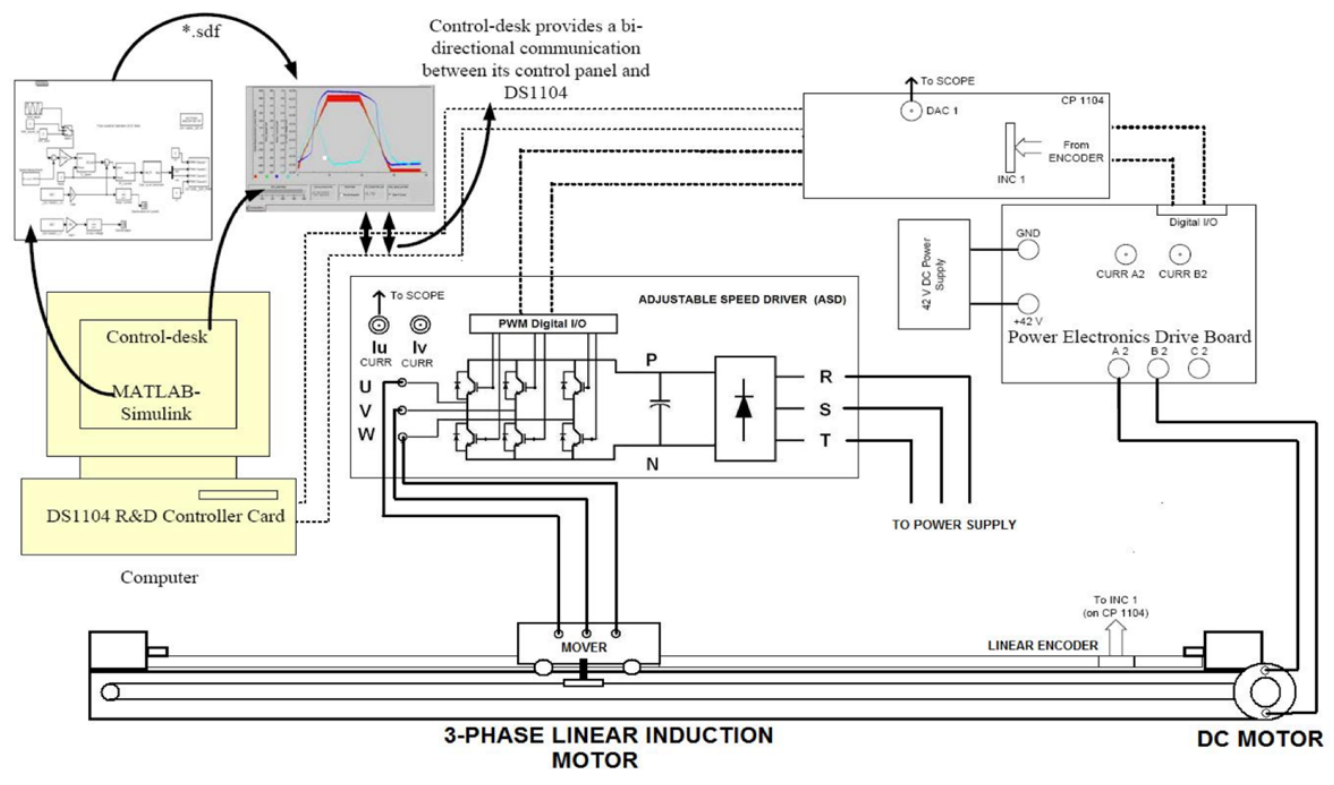

Figure 1. Physical system implemented to obtain the linear induction motor (LIM) model parameters

\section{LIM MODEL CONSIDERING ATTRACTION FORCE AND END-EFFECTS}

Based on the $d-q$ theory, the LIM model has been made with its equivalent circuit starting from [date13]. It is taken into account that the $q$ axis of the linear induction motor is equivalent to the rotary motor so the parameters are invariable. However, if the currents of the $d$ axis are analyzed, they affect the flow of the air gap causing a decrease in $\lambda_{d r}$. Thus the equivalent circuit of the rotary motor in the $d$ axis is not applicable to the linear motor if the edge effects are taken into account.

In rotary motors, the edge effects are not appreciable, which is the case with linear motors. Furthermore, these effects increase as the motor speed increases, which leads to an analysis of these effects as a function of speed, taking into account that they also have different behaviour at the output and arrival ends of the linear motor, since they decrease more slowly at the input than at the output due to the increase in the time constant that modifies the derivative of the function.

\subsection{Equivalent circuit for LIM}

The construction model of the linear motor is illustrated in Figure 2(a). As it can be seen, as the primary moves, it interacts with another region of the liner different from the previous one and that also opposes the increase of penetrating magnetic flux and accumulating more flux in the air gap which affects the performance of the linear motor as reported [17-19]. This effect can be analyzed in Figure 2(c). 


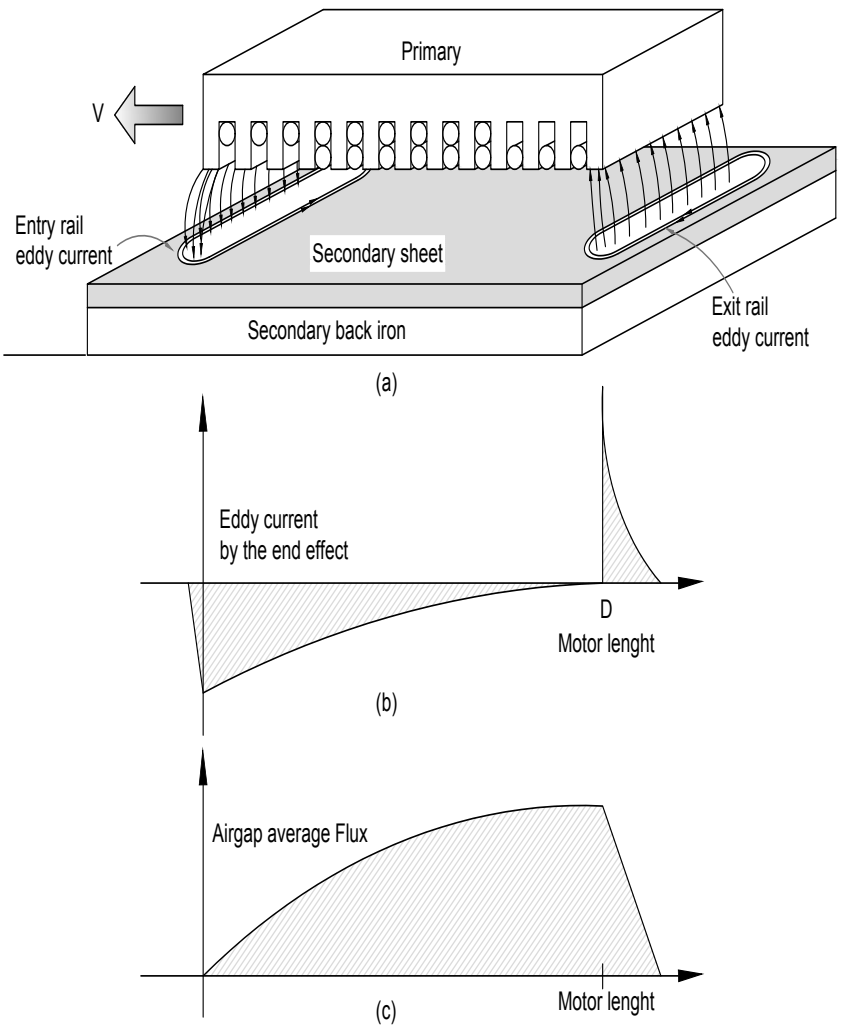

Figure 2. (a) Motion effect of the primary coil generating eddy currents, (b) Input and output current waveforms, (c) Flow waveform in the air gap

As the coils of the primary move, the newly generated field enters the secondary as the previous field disappears at the output of the primary creating eddy currents in the primary [20] (see Figure 3(b)). Aligning the reference frame with the reaction linor flux and call it $d-a x i s$, it results in $\lambda_{q r}=0$. Noting that as far as $\lambda_{q r}=0$ and $\lambda_{d r}$ does not change, the end effect does not play any role in equivalent circuit. Since $i_{q \varepsilon}=-i_{q s}$ the entry $\mathrm{q}$ axis eddy current keeps $\lambda_{q r}=0$. Hence, the $q-$ axis equivalent circuit is identical to the case of the rotary induction motor. However, the $d-$ axis air gap flux is affected much by the eddy current since $\mathrm{d}$-axis entry eddy current in linear induction motor, $i_{d \varepsilon}$, reduces $\lambda_{d r}$.
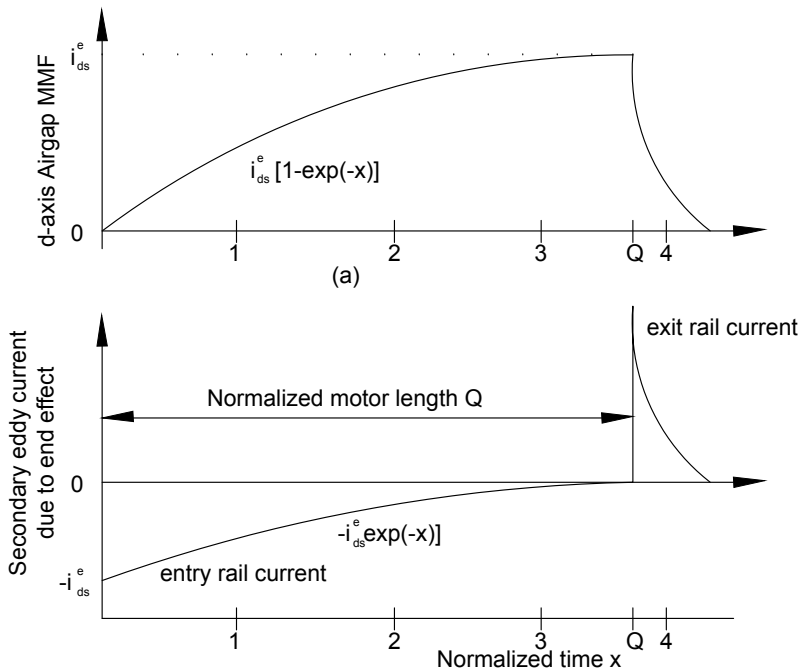

(b)

Figure 3. (a) Effective air gap MMF and (b) eddy current profile in normalized time scale. 


\subsection{Magnetizing inductance reflecting the end effects}

When the primary is moving, the primary MMF observed by the rail will be decreased at the entry and be reflected in the output rail to keep the air gap in flow ( continuous). In particular, the polarity of the input eddy current is contrary to that of the output eddy current, as they are naturally opposed to the generation and extinction of the fields, specifically. Note that the input eddy current has a higher decay period relative to the output eddy current, since the inductance is greater in the air gap than in the free air. The pattern of the eddy currents is drawn in Figure 4 which is based on the standard time scale. [20].

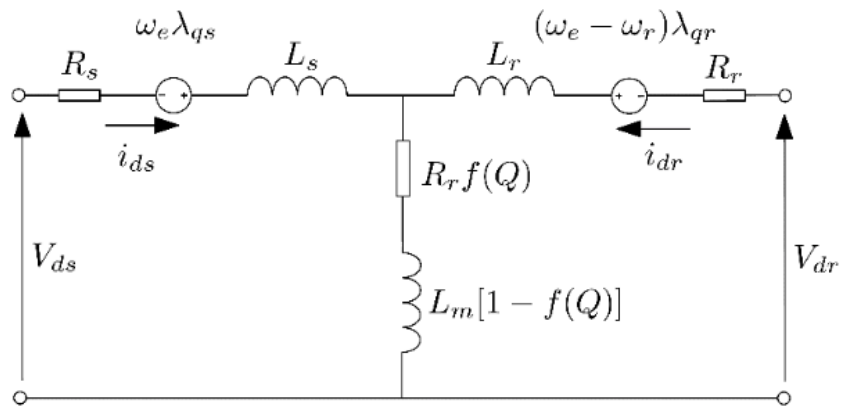

(a)

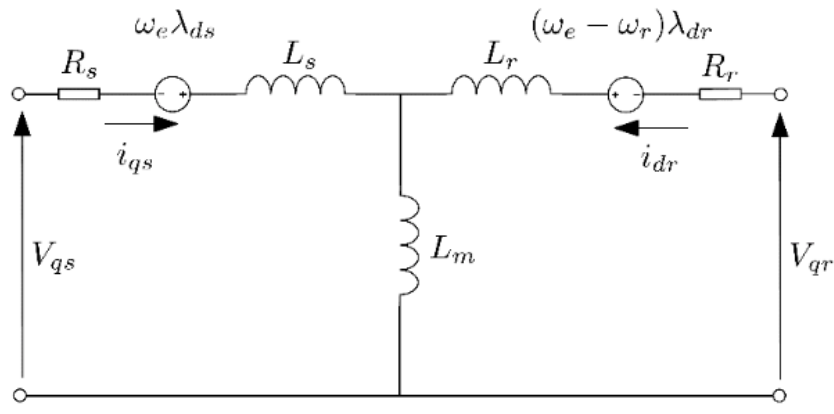

(b)

Figure 4. The equivalent linear motor circuits taking into account the end-effects, (a) The equivalent d-axis circuit, (b) The equivalent q-axis circuit

Observing that the input of the d-axis of the eddy currents decreases with the time differential $T_{r}$, the mean value of the eddy current input from the d-axis $i_{d \varepsilon}$ is given by 1

$$
i_{\varepsilon}=\frac{i_{d s}}{T_{v}} \int_{0}^{T_{v}} e^{-t / T_{r}} d t
$$

where $T_{v}=D / v$, and $D, v$ are the motor extension and velocity. Noting that $T_{v}=D / v$ is the time for the motor to travels a point. Because the travel length for the period $T_{r}$ is eqivalent to $v T_{r}$ and normalizing the motor size with $v T_{r}$ as 2 [21].

$$
Q=\frac{v T_{v}}{v T_{r}}=\frac{D R_{r}}{\left(L_{m}+L_{l r}\right) v}
$$

Notice that $Q$ is non-dimensional yet it represents the length of the motor on the standardized time scale.Based on this, the length of the motor is strongly influenced by the speed of the motor, so that at zero speed, the length of the motor is infinitely long. As the speed increases, the length of the motor will effectively decrease. Using 2, (1) can be rewritten as follows:

$$
i_{\varepsilon}=\frac{i_{d s}}{Q} \int_{0}^{Q} e^{-x} d x=i_{d s} \frac{1-e^{-Q}}{Q}
$$


The effective magnetizing current is thus decreased in such a manner that:

$$
i_{d s}-i_{\varepsilon}=i_{d s}\left[1-\frac{1-e^{-Q}}{Q}\right]
$$

The reduction of the magnetizing current caused by the eddy current, can, however, be justified by changing the magnetizing inductance in a way that:

$$
L_{m}^{\prime}=L_{m}(1-f(Q))
$$

where $f(Q)=\left(1-e^{-Q}\right) / Q$ [20]. As velocity tends to zero, $L_{m}^{\prime}$ converges to $L_{m}$ i.e., the LIM dynamics becomes equivalent to the RIM dynamics as the end effect disappears. Figure 4 shows the effective air gap $\mathrm{MMF}$ and the eddy current profile in normalized time scale.

\subsection{Equivalent series resistor reflecting rail eddy current losses}

When inflow and outflow eddy currents flow along the rail, an ohmic loss of $R_{r}$ will occur. Note that the average square value of the input eddy current over the length of the motor is given by:

$$
i_{\varepsilon R M S}=\left[\frac{i_{d s}^{2}}{Q} \int_{0}^{Q} e^{-2 x} d x\right]^{\frac{1}{2}}=i_{d s}\left[\frac{1-e^{-2 Q}}{2 Q}\right]^{\frac{1}{2}}
$$

Hence, the loss caused by the entry eddy current is evaluated as [22] in 7:

$$
P_{\text {entry }}=i_{\varepsilon R M S}^{2} R_{r}=i_{d s}^{2} R_{r} \frac{1-e^{-2 Q}}{2 Q}
$$

Using the methodology of [22], we can assess the losses due to the eddy current by the temporal rate of the magnetic energy change when exiting the air space of the motor. Note from 3 that the total eddy current in the air gap is equal to $i_{d} s\left(1-e^{-Q}\right)$. This flow must be eliminated in the exit rail for $T_{v}$ to satisfy the steady flow condition of the air gap. Thus, the loss due to the output eddy current is provided by 8 :

$$
P_{\text {exit }}=\frac{L_{r} i_{d s}^{2}\left(1-e^{-Q}\right)^{2}}{2 T_{v}}=i_{d s}^{2} R_{r} \frac{\left(1-e^{-Q}\right)^{2}}{2 Q}
$$

Adding (7) and (8), the total ohmic losses due to eddy currents in the rail are given by this loss of power can be shown as a resistance wired in a series $R_{r} f(Q)$ in the magnetizing current branch. 4 the total ohmic losses due to eddy currents in the rail are given by this loss of power can be shown as a resistance wired in a series.

Duncan's circuit has been developed considering velocity and power loss. It supposes uniform winding and materials, symmetric impedances per phase and equal mutual inductances. It's based on traditional model of three-phase, Y-connected rotatory induction motor whit linear magnetic circuit in a synchronous reference system (superscript "e") aligned with the linor flux. Also only longitudinal end effects have been considered.

Duncan's model has been adopted in order to obtain a space state representation both continuous-time and discrete-time. Several techniques have been developed for non linear dynamics analysis in the state space.

Parameter $Q$, function $f(Q)$, Magnetizing Inductance Reflecting the End Effects and Equivalent Series Resistor Reflecting Rail Eddy Current Losses have been derived from circuit theory.

The $Q$ factor is associated with the length of the primary, and to a certain degree, quantifies the end effects as a function of the velocity $v$ as described by (9).

$$
Q=\frac{D R_{r}}{L_{r} v}
$$

Note that the $Q$ factor is inversely dependent on the velocity, i.e., for a zero velocity the $Q$ factor may be considered infinite, and the end effects may be ignored. As the velocity increases the end effects increases, which causes a reduction of the LIM's magnetization current. This effect may be quantified in terms of the magnetization inductance with the equation: 


$$
L_{m}^{\prime}=L_{m}(1-f(Q))
$$

where $f(Q)=\frac{1-e^{-Q}}{Q}$.

The resistance in series with the inductance $L_{m}^{\prime}$ in the magnetization branch of the equivalent electricalcircuitofthe $d-$ axis, is determined in relation to the increase in losses occurring with the increase of the currents induced at the entry and exit ends of the linor. These losses may be represented as the product of the linor resistance $R_{r}$ by the factor $f(Q)$, ie, $R_{r} f(Q)[23,24]$.

From the $d-q$ equivalent circuit of the LIM, the primary and linor voltage equations in a stationary reference system aligned with the linor flux are given by:

$$
\begin{aligned}
& u_{d s}=R_{s} i_{d s}+R_{r} f(Q)\left(i_{d s}+i_{d r}\right)+\frac{d \alpha_{d s}}{d t} \\
& u_{q s}=R_{s} i_{q s}+\frac{d \alpha_{q s}}{d t} \\
& u_{d r}=R_{r} i_{d r}+R_{r} f(Q)\left(i_{d s}+i_{d r}\right)+\frac{d \alpha_{d r}}{d t}+\frac{\pi}{\tau} v \lambda_{q r} \\
& u_{q r}=R_{r} i_{d r}+\frac{d \alpha_{q r}}{d t}-\frac{\pi}{\tau} v \lambda_{d r}
\end{aligned}
$$

Due to the short-circuited secondary their voltages are zero, that is, $u_{d r}=u_{q r}=0$.

The linkage fluxes are given by the following equations:

$$
\begin{aligned}
& \lambda_{d s}=L_{s} i_{d s}+L_{m} i_{d r}-L_{m} f(Q)\left(i_{d s}+i d r\right) \\
& \lambda_{q s}=L_{s} i_{q s}+L_{m} i_{q r} \\
& \lambda_{d r}=L_{r} i_{d r}+L_{m} i_{d s}-L_{m} f(Q)\left(i_{d s}+i d r\right) \\
& \lambda_{q r}=L_{r} i_{q r}+L_{m} i_{q s}
\end{aligned}
$$

To develop a state space LIM model from 10 and 11 is necessary to combine both equations. Because $q-$ axis equivalent circuit of the LIM is identical to the $q$ - axis equivalent circuit of the induction motor (RIM), the parameters do not vary with the end effects and so $\frac{d \lambda_{q r}}{d t}$ and $\frac{d i_{q s}}{d t}$ in 12 remaind it equals to 13 [6].

$$
\begin{aligned}
\frac{d i_{q s}}{d t} & =-\left[\frac{R_{s}}{\rho L_{s}}+\frac{1-\rho}{\rho T_{r}}\right] i_{q s}-\frac{L_{m} \pi}{\rho L_{s} L_{r} \tau} v \lambda_{d r}+\frac{L_{m}}{\rho L_{s} L_{r} T_{r}} \lambda_{q r}+\frac{1}{\rho L_{s}} u_{q s} \\
\frac{d i_{d s}}{d t} & =-\left[\frac{R_{s}}{\rho L_{s}}+\frac{1-\rho}{\rho T_{r}}\right] i_{d s}+\frac{L_{m}}{\rho L_{s} L_{r} T_{r}} \lambda_{d r}+\frac{L_{m} \pi}{\rho L_{s} L_{r} \tau} v \lambda_{q r}+\frac{1}{\rho L_{s}} u_{d s} \\
\frac{d \lambda_{q r}}{d t} & =\frac{L_{m}}{T_{r}} i_{q s}+\frac{\pi}{\tau} v \lambda_{d r}-\frac{1}{T_{r}} \lambda_{q r} \\
\frac{d \lambda_{d r}}{d t} & =\frac{L_{m}}{T_{r}} i_{d s}-\frac{1}{T_{r}} \lambda_{d r}-\frac{\pi}{\tau} v \lambda_{q r} \\
\frac{d v}{d t} & =\frac{K_{f}}{M}\left(\lambda_{d r} i_{q s}-\lambda_{q r} i_{d s}\right)-\frac{B}{M} v-\frac{F_{L}}{M} \\
\frac{d i_{q s}}{d t} & =-\left[\frac{R_{s}}{\rho L_{s}}+\frac{1-\rho}{\rho T_{r}}\right] i_{q s}-\frac{L_{m} \pi}{\rho L_{s} L_{r} \tau} v \lambda_{d r}+\frac{L_{m}}{\rho L_{s} L_{r} T_{r}} \lambda_{q r}+\frac{1}{\rho L_{s}} u_{q s} \\
\frac{d \lambda_{q r}}{d t} & =\frac{L_{m}}{T_{r}} i_{q s}+\frac{\pi}{\tau} v \lambda_{d r}-\frac{1}{T_{r}} \lambda_{q r}
\end{aligned}
$$

The RIM electrical torque in an arbitrary reference frame is giving by [19], and modifying it with relation $v=\tau \frac{\omega_{1}}{\pi}=2 \tau f_{1}$ we obtain following LIM thrust force.

$$
F_{e}=\frac{3}{2} \frac{\pi}{\tau \omega_{r}}\left[\omega\left(\lambda_{d s} i_{q s}-\lambda_{q s} i_{d s}\right)+\left(\omega-\omega_{r}\right)\left(\lambda_{d r} i_{q r}-\lambda_{q r} i_{d r}\right)\right]
$$

in a stationary reference frame $(\omega=0)$ the thrust force becomes:

$$
F_{e}=\frac{3}{2} \frac{\pi}{\tau}\left[\lambda_{q r} i_{d r}-\lambda_{d r} i_{q r}\right]
$$


clearing $i_{d r}$ from $\lambda_{d} r$ in 11

$$
i_{d r}=\frac{\lambda_{d r}-L_{m}(1-f(Q)) i_{d s}}{L_{r}-L_{m} f(Q)}
$$

clearing $i_{q} r$ from $\lambda_{q} r$ in 11

$$
i_{q r}=\frac{\lambda_{q r}-L_{m} i_{q s}}{L r}
$$

Substituting $i_{d r}$ and $i_{q r}$ into 14 results in:

$$
F_{e}=\frac{3}{2} \frac{\pi}{\tau} \frac{L_{m}}{L_{r}}\left[\lambda_{d r} i_{q s}+\frac{f(Q)}{L_{r}-L_{m} f(Q)} \lambda_{q r} \lambda_{d r}-\frac{1-f(Q)}{L_{r}} \lambda_{q r} i_{d s}\right]
$$

Then space state mechanical equation is giving by 18

$$
\frac{d v}{d t}=\frac{K_{f}}{M}\left[\lambda_{d r} i_{q s}+\frac{f(Q)}{L_{r}-L_{m} f(Q)} \lambda_{q r} \lambda_{d r}-\frac{1-f(Q)}{1-\frac{L m}{L_{r}} f(Q)} \lambda_{q r} i_{d s}\right]-\frac{B}{M} v-\frac{F_{L}}{M}
$$

Considering short-circuited linor circuit $\left(u_{d r}=0\right)$ and solving for $\frac{d \lambda_{d r}}{d t}$ gets

$$
\frac{d \lambda_{d r}}{d t}=-\frac{R_{r}(1+f(Q))}{L_{r}-L_{m} f(Q)} \lambda_{d r}-\frac{\pi}{\tau} v \lambda_{q r}+\frac{R_{r}\left(L_{m}-L_{r} f(Q)\right)}{L_{r}-L_{m} f(Q)} i_{d s}
$$

Substituting the first equation of 11 into first equation of 10 results:

$$
\begin{aligned}
u_{d s}= & {\left[R_{s}+R_{r} f(Q)-L_{m} \frac{d f(Q)}{d t}\right] i_{d s}+\left[L_{s}-L_{m} f(Q)\right] \frac{d i_{d s}}{d t} } \\
& +L_{m}[1-f(Q)] \frac{d i_{d r}}{d t}-L_{m} \frac{d f(Q)}{d t} i_{d r}
\end{aligned}
$$

Clearing $i_{d r}$ from $\lambda_{d r}$ in 11

$$
i_{d r}=\frac{1}{L_{r}-L_{m} f(Q)} \lambda_{d r}-\frac{L_{m}(1-f(Q))}{L_{r}-L_{m} f(Q)} i_{d s}
$$

and substituting into 20 results

$$
\begin{aligned}
u_{d s}= & {\left[R_{s}+R_{r} f(Q)-\frac{\left(L_{r}-L_{m}\right)^{2}}{\left(L_{r}-L_{m} f(Q)\right)^{2}} L_{m} \frac{d f(Q)}{d t}\right] i_{d s} } \\
& +\left[L_{s}-L_{m} f(Q)-\frac{L_{m}^{2}(1-f(Q))^{2}}{L_{r}-L_{m} f(Q)}\right] \frac{d i_{d s}}{d t} \\
& +\frac{L_{m}\left(L_{m}-L_{r}\right)}{\left(L_{r}-L_{m} f(Q)\right)^{2}} \frac{d f(Q)}{d t} \lambda_{d r}+\frac{L_{m}(1-f(Q))}{L_{r}-L_{m} f(Q)} \frac{d \lambda_{d r}}{d t}
\end{aligned}
$$

substituting $\frac{d \lambda_{d r}}{d t}$ in last term into above equation we obtain:

$$
\begin{aligned}
u_{d s}= & {\left[R_{s}+R_{r} f(Q)-\frac{\left(L_{r}-L_{m}\right)^{2}}{\left(L_{r}-L_{m} f(Q)\right)^{2}} L_{m} \frac{d f(Q)}{d t}+\frac{R_{r} L_{m}(1-f(Q))}{L_{r}-L_{m} f(Q)} \frac{\left(L_{m}-L_{r} f(Q)\right)}{L_{r}-L_{m} f(Q)}\right] i_{d s} } \\
& +\left[L_{s}-L_{m} f(Q)-\frac{L_{m}^{2}(1-f(Q))^{2}}{L_{r}-L_{m} f(Q)}\right] \frac{d i_{d s}}{d t} \\
& +\left[\frac{L_{m}\left(L_{m}-L_{r}\right)}{\left(L_{r}-L_{m} f(Q)\right)^{2}} \frac{d f(Q)}{d t}-\frac{R_{r} L_{m}\left(1-f^{2}(Q)\right)}{\left(L_{r}-L_{m} f(Q)\right)^{2}}\right] \lambda_{d r}-\frac{L_{m}(1-f(Q))}{L_{r}-L_{m} f(Q)} \frac{\pi}{\tau} v \lambda_{q r}
\end{aligned}
$$


Solving for $\frac{d i_{d s}}{d t}$

$$
\begin{aligned}
\frac{d i_{d s}}{d t}= & \frac{\left[R_{s}+R_{r} f(Q)\right]\left[L_{r}-L_{m} f(Q)\right]^{2}-L_{m}\left(L_{r}-L_{m}\right)^{2} \frac{d f(Q)}{d t}+R_{r} L_{m}[1-f(Q)]\left[L_{m}-L_{r} f(Q)\right]}{\left[L_{S} L_{r}-L_{s} L_{m} f(Q)-L_{r} L_{m} f(Q)-L_{m}^{2}+2 L_{m}^{2} f(Q)\right]\left[L_{m} f(Q)-L_{r}\right]} l_{d s} \\
& +\frac{L_{m}\left(L_{m}-L_{r}\right) \frac{d f(Q)}{d t}-R_{r} L_{m}\left[1-f^{2}(Q)\right]}{\left[L_{s} L_{r}-L_{s} L_{m} f(Q)-L_{r} L_{m} f(Q)-L_{m}^{2}+2 L_{m}^{2} f(Q)\right]\left[L_{m} f(Q)-L_{r}\right]} \lambda_{d r} \\
& +\frac{L_{m}[1-f(Q)]}{L_{s} L_{r}-L_{S} L_{m} f(Q)-L_{r} L_{m} f(Q)-L_{m}^{2}+2 L_{m}^{2} f(Q)} \frac{\pi}{\tau} v \lambda_{q r} \\
& +\frac{L_{r}-L_{m} f(Q)}{L_{s} L_{r}-L_{S} L_{m} f(Q)-L_{r} L_{m} f(Q)-L_{m}^{2}+2 L_{m}^{2} f(Q)} u_{d} s
\end{aligned}
$$

Grouping the state equations and changing the index $\mathrm{d}$ and $\mathrm{q}$ by $\alpha$ and $\beta$ respectively, and omitting the primary and secondary (linor) indexes because the voltages and currents are with respect to primary and the fluxes are with respect to secondary, we obtain 22 :

$$
\begin{aligned}
& \frac{d i_{\beta}}{d t}=-\left[\frac{R_{S}}{\rho L_{S}}+\frac{1-\rho}{\rho T_{r}}\right] i_{\beta}-\frac{L_{m} \pi}{\rho L_{S} L_{r} \tau} v \lambda_{\alpha}+\frac{L_{m}}{\rho L_{S} L_{r} T_{r}} \lambda_{\beta}+\frac{1}{\rho L_{S}} u_{\beta} \\
& \frac{d i_{\alpha}}{d t}=\frac{\left[R_{S}+R_{r} f(Q)\right]\left[L_{r}-L_{m} f(Q)\right]^{2}-L_{m}\left(L_{r}-L_{m}\right)^{2} \frac{d f(Z)}{d t}+R_{r} L_{m}[1-f(Q)]\left[L_{m}-L_{r} f(Q)\right]}{\left[L_{S} L_{r}-L_{S} L_{m} f(Q)-L_{r} L_{m} f(Q)-L_{m}^{2}+2 L_{m}^{2} f(Q)\right]\left[L_{m} f(Q)-L_{r}\right]} i_{\alpha} \\
& +\frac{L_{m}\left(L_{m}-L_{r}\right) \frac{d f(Q)}{d t}-R_{r} L_{m}\left[1-f^{2}(Q)\right]}{\left[L_{S} L_{r}-L_{S} L_{m} f(Q)-L_{r} L_{m} f(Q)-L_{m}^{2}+2 L_{m}^{2} f(Q)\right]\left[L_{m} f(Q)-L_{r}\right]} \lambda_{\alpha} \\
& +\frac{L_{m}[1-f(Q)]}{L_{s} L_{r}-L_{s} L_{m} f(Q)-L_{r} L_{m} f(Q)-L_{m}^{2}+2 L_{m}^{2} f(Q)} v \lambda_{\beta} \\
& +\frac{L_{r}-L_{m} f(Q)}{L_{S} L_{r}-L_{S} L_{m} f(Q)-L_{r} L_{m} f(Q)-L_{m}^{2}+2 L_{m}^{2} f(Q)} u_{\alpha} \\
& \frac{d \lambda_{\beta}}{d t}=\frac{L_{m}}{T_{r}} i_{\beta}+\frac{\pi}{\tau} v \lambda_{\alpha}-\frac{1}{T_{r}} \lambda_{\beta} \\
& \frac{d \lambda_{\alpha}}{d t}=-\frac{R_{r}(1+f(Q))}{L_{r}-L_{m} f(Q)} \lambda_{\alpha}-\frac{\pi}{\tau} v \lambda_{\beta}+\frac{R_{r}\left(L_{m}-L_{r} f(Q)\right)}{L_{r}-L_{m} f(Q)} i_{\alpha} \\
& \frac{d v}{d t}=\frac{K_{f}}{M}\left[\lambda_{\alpha} i_{\beta}+\frac{1-f(Q)}{L_{r}-L_{m} f(Q)} \lambda_{\beta} \lambda_{\alpha}-\frac{\left.1-\frac{L_{m} f(Q)}{L_{r}} i_{\alpha}\right]-\frac{B}{M} v-\frac{F_{L}}{M}}{\frac{d x}{d t}}=v\right.
\end{aligned}
$$

where $v$ is the mover linear velocity; $\lambda_{\alpha}$ and $\lambda_{\beta}$ are the $d$-axis an $q$-axis secondary flux; $i_{\alpha}$ and $i_{\beta}$ are the $d$-axis and $q$-axis primary current; $u_{\alpha}$ and $u_{\beta}$ are the $d$-axis and $q$-axis primary voltage; $T_{r}=\frac{L_{r}}{R_{r}}$ is the secondary time constant; $\rho=1-\frac{L_{m}^{2}}{L_{s} L_{r}}$ is the leakage coefficient; $K_{f}=\frac{3}{2} \frac{\pi L_{m}}{\tau L_{r}}$ is the force constant; $R_{s}$ is the winding resistance per phase; $R_{r}$ is the secondary resistance per phase referred primary; $L_{m}$ is the magnetizing inductance per phase; $L_{r}$ is the secondary inductance per phase referred primary; $L_{s}$ is the primary inductance per phase; $F_{L}$ is the external force disturbance; $M$ is the total mass of the mover; $B$ is the viscous friction and iron-loss coefficient; $\tau$ is the pole pitch; $D$ is the primary length in meters; $Q=\frac{D R_{r}}{L_{r} v}$ is a factor related to the primary length, which quatifies the end effects as a function of the speed and $f(Q)=\frac{1-e^{-Q}}{Q}$ is the factor related to the losses in the magnetization branch. To discretize the state LIM model with end effects we use the backward difference method [25] and finally we obtain an approximate discrete time version of the LIM model 23 taking into account end effects. 


$$
\begin{aligned}
& i_{k+1}^{\beta}=i_{k}^{\beta}-\left[\frac{R_{S}}{\rho L_{S}}+\frac{1-\rho}{\rho T_{r}}\right] T i_{k}^{\beta}-\frac{L_{m} \pi}{\rho L_{S} L_{r} \tau} T v_{k} \lambda_{k}^{\alpha}+\frac{L_{m}}{\rho L_{S} L_{r} T_{r}} T \lambda_{k}^{\beta}+\frac{1}{\rho L_{S}} T u_{k}^{\beta} \\
& i_{k+1}^{\alpha}=i_{k}^{\alpha}+\frac{\left[R_{s}+R_{r} f(Q)\right]\left[L_{r}-L_{m} f(Q)\right]^{2}-L_{m}\left(L_{r}-L_{m}\right)^{2} \frac{\Delta f(Q)}{T}+R_{r} L_{m}[1-f(Q)]\left[L_{m}-L_{r} f(Q)\right]}{\left[L_{s} L_{r}-L_{s} L_{m} f(Q)-L_{r} L_{m} f(Q)-L_{m}^{2}+2 L_{m}^{2} f(Q)\right]\left[L_{m} f(Q)-L_{r}\right]} T i_{k}^{\alpha} \\
& +\frac{L_{m}\left(L_{m}-L_{r}\right) \frac{\Delta f(Q)}{T}-R_{r} L_{m}\left[1-f^{2}(Q)\right]}{\left[L_{S} L_{r}-L_{S} L_{m} f(Q)-L_{r} L_{m} f(Q)-L_{m}^{2}+2 L_{m}^{2} f(Q)\right]\left[L_{m} f(Q)-L_{r}\right]} T \lambda_{k}^{\alpha} \\
& +\frac{L_{m}[1-f(Q)]}{L_{s} L_{r}-L_{s} L_{m} f(Q)-L_{r} L_{m} f(Q)-L_{m}^{2}+2 L_{m}^{2} f(Q)} T v_{k} \lambda_{k}^{\beta} \\
& +\frac{L_{r}-L_{m} f(Q)}{L_{s} L_{r}-L_{s} L_{m} f(Q)-L_{r} L_{m} f(Q)-L_{m}^{2}+2 L_{m}^{2} f(Q)} T u_{k}^{\alpha} \\
& \lambda_{k+1}^{\beta}=\lambda_{k}^{\beta}+\frac{L_{m}}{T_{r}} T i_{k}^{\beta}+\frac{\pi}{\tau} T v_{k} \lambda_{k}^{\alpha}-\frac{1}{T_{r}} T \lambda_{k}^{\beta} \\
& \lambda_{k+1}^{\alpha}=\lambda_{k}^{\alpha}-\frac{R_{r}(1+f(Q))}{L_{r}-L_{m} f(Q)} T \lambda_{k}^{\alpha}-\frac{\pi}{\tau} T v_{k} \lambda_{k}^{\beta}+\frac{R_{r}\left(L_{m}-L_{r} f(Q)\right)}{L_{r}-L_{m} f(Q)} T i_{k}^{\alpha} \\
& v_{k+1}=v_{k}+\frac{K_{f}}{M} T\left[\lambda_{k}^{\alpha} i_{k}^{\beta}+\frac{f(Q)}{L_{r}-L_{m} f(Q)} \lambda_{k}^{\beta} \lambda_{k}^{\alpha}-\frac{1-f(Q)}{1-\frac{L m}{L_{r}} f(Q)} \lambda_{k}^{\beta} i_{k}^{\alpha}\right]-\frac{B}{M} T v_{k}-\frac{F_{L}}{M} T \\
& x_{k+1}=x_{k}+v_{k} T
\end{aligned}
$$

where $v_{k}=v(k T)$ is the mover linear velocity; $\lambda_{k}^{\alpha}=\lambda_{\alpha}(k T)$ and $\lambda_{k}^{\beta}=\lambda_{\beta}(k T)$ are the $d-$ axis an $q$-axis secondary flux; $i_{k}^{\alpha}=i_{\alpha}(k T)$ and $i_{k}^{\beta}=i_{\beta}(k T)$ are the $d-$ axis and $q$-axis primary current; $u_{k}^{\alpha}=u_{\alpha}(k T)$ and $u_{k}^{\beta}=u_{\beta}(k T)$ are the $d-$ axis and $q$-axis primary voltage; $T_{r}=\frac{L_{r}}{R_{r}}$ is the secondary time constant; $\rho=1-\left(\frac{L_{m}^{2}}{L_{s} L_{r}}\right)$ is the leakage coefficient; $K_{f}=\frac{3}{2} \frac{\pi L_{m}}{\tau L_{r}}$ is the force constant; $R_{s}$ is the winding resistance per phase; $R_{r}$ is the secondary resistance per phase referred primary; $L_{m}$ is the magnetizing inductance per phase; $L_{r}$ is the secondary inductance per phase referred primary; $L_{s}$ is the primary inductance per phase; $F_{L}$ is the external force disturbance; $M$ is the total mass of the mover; $B$ is the viscous friction and iron-loss coefficient; $\tau$ is the pole pitch; $D$ is the primary length in meters; $Q=\frac{D R_{r}}{L_{r} v_{k}}$ is a factor related to the primary length, which quantifies the end effects as a function of the speed; $f(Q)=\frac{1-e^{-Q}}{Q}$ is the factor related to the losses in the magnetization branch and $\frac{\Delta f(Q)}{T}=\left.\frac{d f(Q)}{d t}\right|_{t=k T}$.

\section{RESULTS}

Figure 5 shows the end effects on mover velocity, fluxes and currents. Figures 6, 7 and 8 show the system 22 behavior when the frequency of input voltage vary. The steady state velocity is a periodic wave in all cases, but when the fed frequency is lower, higher output frequency components appear. Phase portraits in subfigures $6 \mathrm{~b}, 6 \mathrm{c}, 7 \mathrm{~b}, 7 \mathrm{c}, 8 \mathrm{~b}$ and $8 \mathrm{c}$ with attractive limit cycles are shown.

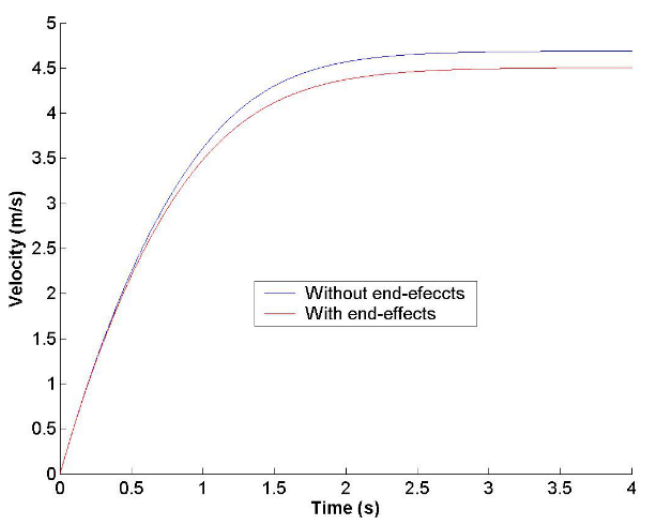

(a)

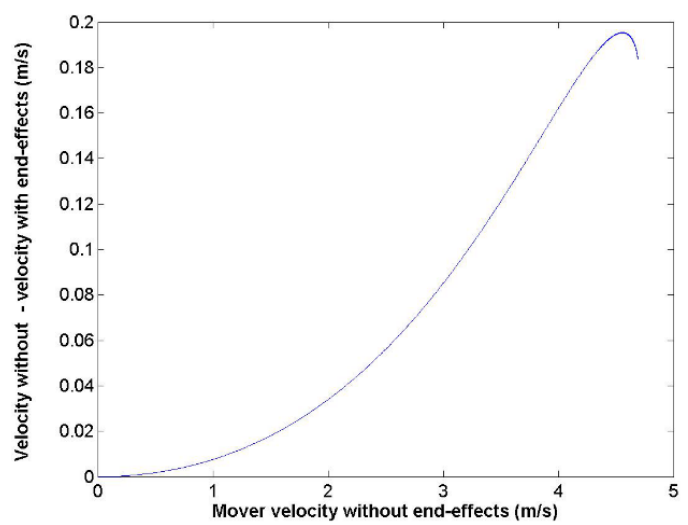

(b) 


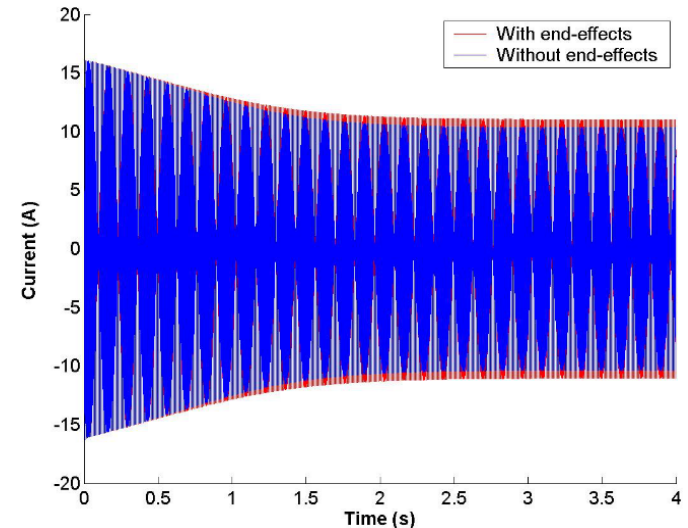

(c)

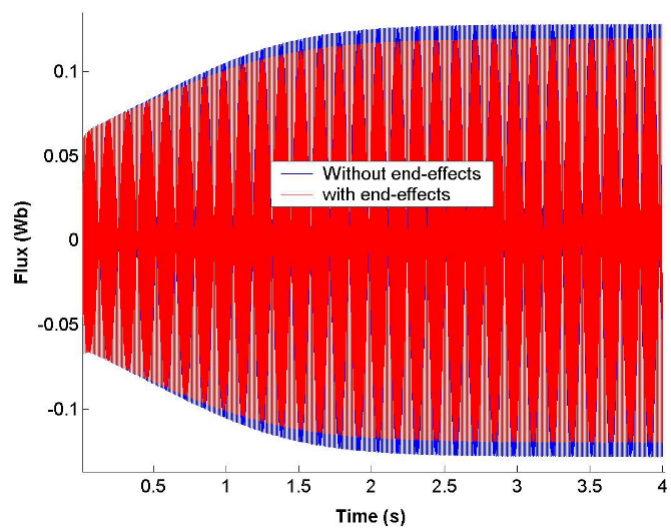

(d)

Figure 5. Mover velocity, velocity differences, currents and fluxes resulting from the model simulation using ODE45 function of Matlab, taking into account end effects in model of LIM (22) and without end-effects model (3), (a) Mover velocity of LIM with and without end-effects, (b) Velocity difference vs mover velocity without end-effects, (c) $\beta$ - axis With and without end-effects currents,

(d) $\beta$ - axis With and without end-effects fluxes (continue)

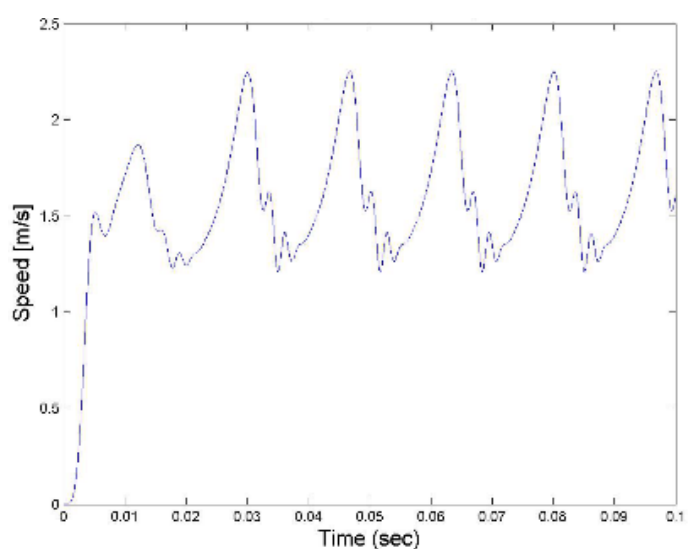

(a)

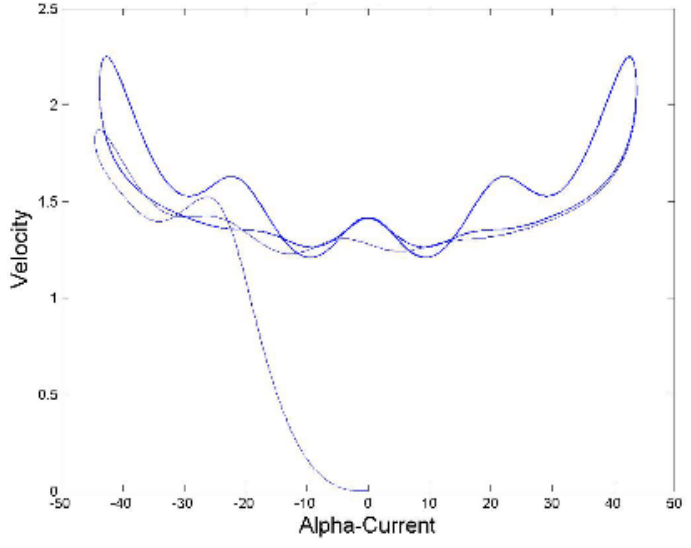

(b)

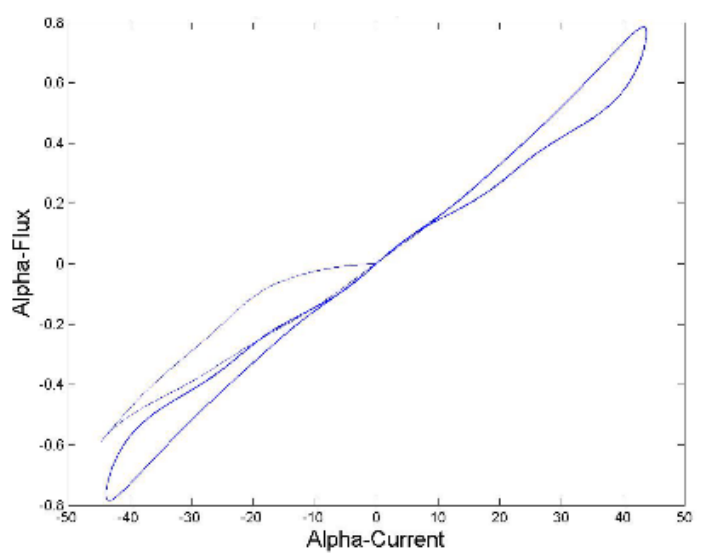

(c)

Figure 6. LIM behavior with $30 \mathrm{~Hz}$ input frequency. Mover velocity and phase portraits of some state variables, (a) Mover velocity of LIM with end-effects, (b) Phase portrait of mover velocity vs $i_{\alpha}$,

(c) Phase portrait of $\lambda_{\alpha}$ vs $i_{\alpha}$ 


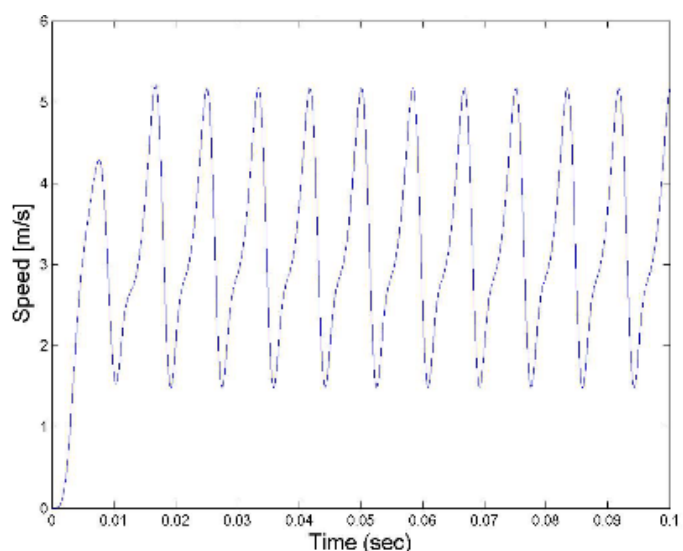

(a)

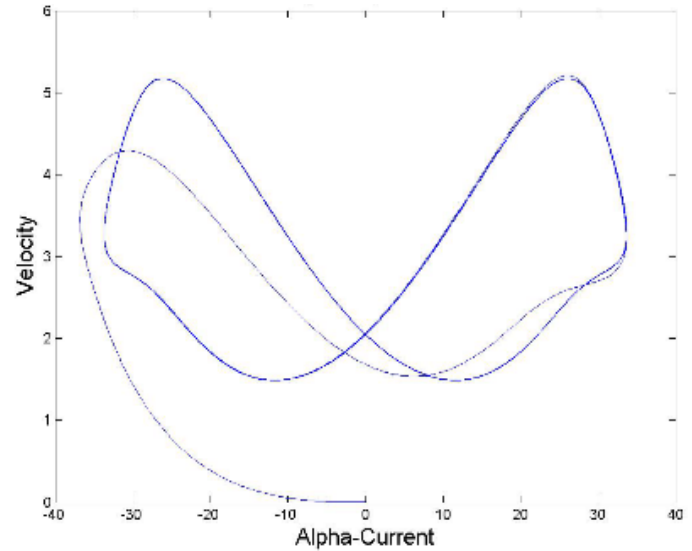

(b)

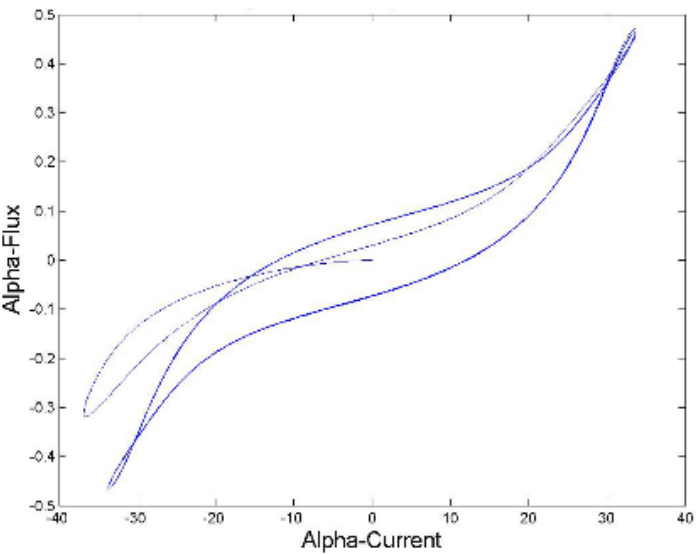

(c)

Figure 7. LIM behavior with $60 \mathrm{~Hz}$ input frequency. Mover velocity and phase portraits of some state variables, (a) Mover velocity of LIM with end-effects, (b) Phase portrait of mover velocity vs $i_{\alpha}$, (c) Phase portrait of $\lambda_{\alpha}$ vs $i_{\alpha}$

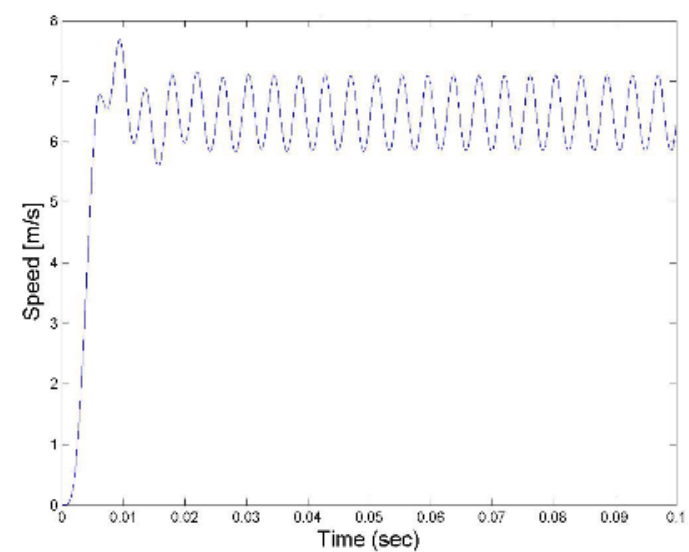

(a)

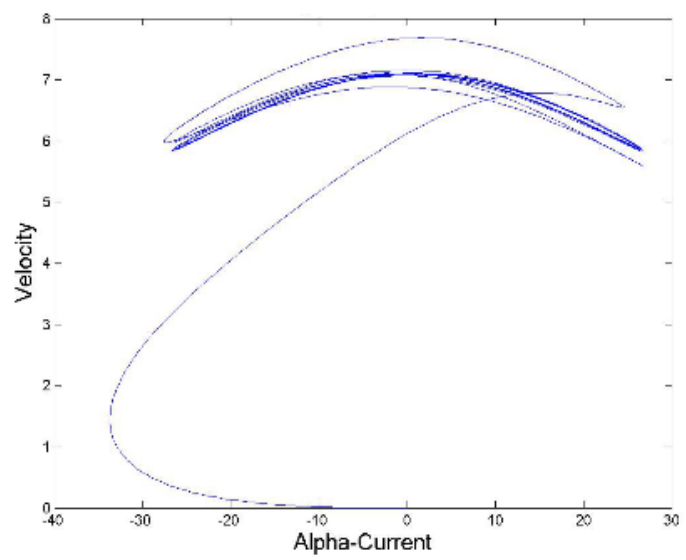

(b) 


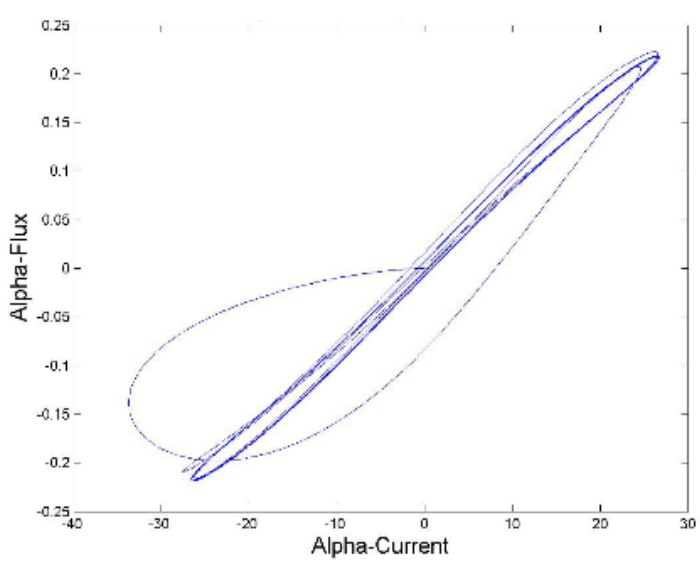

(c)

Figure 8. LIM behavior with $120 \mathrm{~Hz}$ input frequency. Mover velocity and phase portraits of some state variables, (a) Mover velocity of LIM with end-effects, (b) Phase portrait of mover velocity vs $i_{\alpha}$,

(c) Phase portrait of $\lambda_{\alpha}$ vs $i_{\alpha}$ (continue)

\section{CONCLUSIONS}

The continuous model of the linear induction motor (LIM) has been made considering the edge effects and the attraction force. A laboratory prototype has been implemented from which the parameters of the equivalent LIM circuit have been obtained. The discrete model has been developed to quickly obtain computational solutions and to analyze non-linear behaviors through the application of discrete control systems. In order to obtain the discrete model of the LIM we have started from the solution of the continuous model. To develop the model, the magnetizing inductance has been considered, which reflects the edge effects. The model is compared with and without considering the edge effects. The edge effects show a decreasing in the mover velocity at steady state due to lose power in the magnetization. In the primary current there is an increase due the power requirements to supply the magnetic loses. The phase portraits were developed shown high frequency components in velocity mover with low frequencies in the supply currents.

\section{ACKNOWLEDGEMENT}

This work was supported by the Universidad Nacional de Colombia, Sede Medellín, grupo de investigación en Procesamiento Digital de Señales para Sistemas en Tiempo Real under the projects HERMES-34671 and HERMES-36911, the Grupo de Investigación en Recursos Energéticos GIRE at the Universidad Nacional de Colombia, and the Universidad Católica de Manizales with the Grupo de Investigación en Desarrollos Tecnológicos y Ambientales GIDTA. The authors thank the School of Physics for their valuable support given to the conduction of this research. This research paper corresponds to "programa reconstrucción del tejido social en zonas de pos-conflicto en Colombia del proyecto Modelo ecosistémico de mejoramiento rural y construcción de paz: instalación de capacidades locales," and is financed by the "Fondo Nacional de Financiamiento para la Ciencia, la Tecnología, y la Innovación, Fondo Francisco José de Caldas con contrato No 213-2018 con Código 58960.” Programa “Colombia Científica”.

\section{REFERENCES}

[1] N. H. Quang, et al., "Multi parametric model predictive control based on laguerre model for permanent magnet linear synchronous motors," International Journal of Electrical and Computer Engineering (IJECE), vol. 9, no. 2, pp. 1067-1077, 2019.

[2] N. Toro-García, Y. A. Garcés-Gómez, and Fredy E. Hoyos "Parameter estimation of three-phase linear induction motor by a DSP-based electric-drives system," International Journal of Electrical and Computer Engineering (IJECE), vol. 10, no. 1, pp. 626-636, 2020. 
[3] N. H. Quang, et al., "Multi parametric model predictive control based on laguerre model for permanent magnet linear synchronous motors," International Journal of Electrical and Computer Engineering (IJECE), vol. 9, no. 2, pp. 1067-1077, 2019.

[4] Nasar, S.A., and Boldea, I., "Linear Electric Motors: Theory, Design and Practical Applications," Prentice Hall Trade, 1987.

[5] Nasar, S.A., and Boldea, I., "Linear Motion Electric Machines," John Wiley Sons Inc, 1976.

[6] Boldea, I., and Nasar, S.A., "Linear Electric Actuators and Generators," Cambridge University Press, 2005.

[7] Toro-García, N., Garcés-Gómez, Y. A., and Hoyos, F. E., "Discrete and Continuous Model of Three-Phase Linear Induction Motors "LIMs" Considering Attraction Force," Energies, vol. 12, 2019.

[8] N. H. Quang, et al., "Min Max Model Predictive Control for Polysolenoid Linear Motor," International Journal of Power Electronics and Drive System(IJPEDS), vol. 9, no. 4, pp. 1666-1675, 2018.

[9] F. Berrezzek, W. Bourbia, and B. Bensaker "A comparative study of nonlinear circle criterion based observer and H observer for induction motor drive," International Journal of Power Electronics and Drive System (IJPEDS), Vol. 10, No. 3, Sep 2019, pp. 1229-1243,

[10] Xu, W., Zhu, J., Guo, Y., and Wang, Y. "Equivalent circuits for single-sided linear induction motors," In Proceedings of the 2009 IEEE Energy Conversion Congress and Exposition, pp. 1288-1295, 2009.

[11] Du, Y., and Jin, N. "Research on characteristics of single-sided linear induction motors for urban transit," In Proceedings of the 2009 International Conference on Electrical Machines and Systems, pp. 1-4, 2009.

[12] Faiz, J., and Jagari, H., "Accurate modeling of single-sided linear induction motor considers end effect and equivalent thickness," IEEE Trans. Magn, vol. 36, pp.3785-3790, 2006.

[13] H. Sathishkumar, and S. S. Parthasarathy, "Identification of robust controller for 3hp 3phases induction motor," International Journal of Robotics and Automation (IJRA), vol. 8, no. 1, pp. 125-132, 2019.

[14] Liu, J., Lin, F., Yang, Z., and Zheng, T. Q., "Field oriented control of linear induction motor considering attraction force and end-effects," In Proceedings of the International Power Electronics and Motion Control Conference IPEMC, 2006.

[15] Thang Nguyen Trong., "The Neural Network-Combined Optimal Control System of Induction Motor," International Journal of Electrical and Computer Engineering (IJECE), vol. 9, no. 4, pp. 2513-2522, 2019.

[16] Fernandes, E., dosSantos, C. C., and Lima, J. W., "Field oriented control of linear induction motor taking into account end-effects," In Proceedings of the AMC, pp. 689-694, 2004.

[17] Benitez, V. H., Sanchez, E. N., and Loukianov, A. G. "Neural identification and control for linear induction motors," J. Intell. Fuzzy Syst, vol. 16, pp. 33-55, 2005.

[18] Hernández-Márquez, et al., "Robust Tracking Controller for a DC/DC Buck-Boost Converter-Inverter-DC Motor System," Energies, vol. 11, 2018.

[19] A. Hamed, and A. Hazzab., "Modeling and Real-Time Simulation of Induction Motor Using RT-LAB," International Journal of Power Electronics and Drive System (IJPEDS), vol. 9, no. 4, pp. 1476-1485, 2018.

[20] A. Boucheta, et al., "Linear induction motor control using sliding mode considering the end effects," 6th International Multi-Conference on Systems, Signals and Devices, pp. 1-6, 2009.

[21] H. Velasco, F. E., Candelo-Becerra, J. E., and R. Santamaría, A., "Dynamic Analysis of a Permanent Magnet DC Motor Using a Buck Converter Controlled by ZAD-FPIC," Energies, vol. 11, 2018.

[22] Duncan, J. "Linear induction motor-equivalent-circuit model," Proc. IEE, vol. 130, no. 1, pp. 51-57, 1983.

[23] Loukianov, A. G., Rivera, J., and Cañedo, J.M., "Discrete-time sliding mode control of an induction motor," In Proceedings of the 15th World Congress of IFAC, vol. 1, pp. 106-111, 2002.

[24] J. Duncan. "Linear induction motor-equivalent-circuit model", Proc. IEEE, vol. 130, no. 1, pp. 51-57, 1983.

[25] Chee-Mun Ong. "Dynamic Simulation of Electric Machinery Using Matlab/Simulink," Prentice Hall, 1998. 